\title{
Discursos Identitários E A Posição Como Sujeito Terranovense
}

\author{
Discursos Idenitários Y La Posición Como Sujeto Terranovense \\ Indential Remarks And The Position As Subject Terranovense
}

\author{
Vanderley da Silva ${ }^{1}$ \\ Rosana Rodrigues da Silva ${ }^{2}$
}

\begin{abstract}
Resumo
Este trabalho tem por objetivo principal trazer algumas reflexões vinculadas aos discursos identitários, bem como a posição sujeito terranovense de três entrevistados que chegaram ainda crianças, juntamente, ao local. A pesquisa foi realizada a partir dos procedimentos da História Oral Temática, por meio de entrevistas com perguntas relacionadas ao posicionamento dos três filhos de colonizadores do município de Terra Nova do Norte, em Mato Grosso. O aporte teórico fundamentou-se nas contribuições de Stuart Hall (2006), Hugo Achugar (2016), Homi Bhabha (1998) e Zygmunt Bauman (2005).
\end{abstract}

Palavras-Chave: Discursos Identitários. Filhos De Colonos. Terra Nova Do Norte.

\section{Resumen}

Este trabajo tiene por objetivo principal traer algunas reflexiones vinculadas a los discursos identitários, así como la posición sujeto terranovense de tres entrevistados que llegaron aún niños, junto, al local. La investigación fue realizada a partir de los procedimientos de la Historia Oral Temática, por medio de entrevistas con preguntas relacionadas al posicionamiento de los tres hijos de colonizadores del municipio de Terra Nova do Norte, en Mato Grosso. El aporte teórico se fundó en las contribuciones de Stuart Hall (2006), Hugo Achucar (2016), Homi Bhabha (1998) y Zygmunt Bauman (2005).

Palabras Clave: Discursos Identitarios. Hijos De Colonos. Tierra Nueva Del Norte.

\begin{abstract}
This work has as main objective to bring some reflections related to the identitary discourses, as well as the terranovense subject position of three interviewees who still arrived children, together, to the place. The research was carried out using Oral History Thematic procedures, through interviews with questions related to the positioning of the three children of settlers of the municipality of Terra Nova do Norte, in Mato Grosso. The theoretical contribution was based on the contributions of Stuart Hall (2006), Hugo Achugar (2016), Homi Bhabha (1998) and Zygmunt Bauman (2005).
\end{abstract}

Keywords: Identity Discourses. Children Of Settlers. Newfoundland Of The North.

\footnotetext{
${ }^{1}$ Mestrando em Letras pelo Programa de Pós-graduação em Letras da Universidade do Estado de Mato Grosso UNEMAT - Campus de Sinop. Linha de Pesquisa: Estudos Literários. E-mail: vanderleydasilva2009@hotmail.com.

${ }^{2}$ Doutora em Letras pela UNESP de São José do Rio Preto. Mestre em Letras pela UFRGS e Graduada em Letras pela UNESP, campus de Assis. Professora da UNEMAT, (Universidade do Estado do Mato Grosso), campus de Sinop, do curso de graduação em Letras; Mestrado profissionalizante (PROFLETRAS) e do Mestrado acadêmico (PPGLetras). E-mail: rosana.rodrigues@unemat-net.br
} 


\title{
1. Introdução
}

De acordo com Stuart Hall (2006) a identidade é formada temporalmente por meio de processos inconscientes. Não é inata e permanece sempre incompleta, "em processo", em formação. Assim, este trabalho intenta analisar os discursos de três pessoas nascidas no Rio Grande do Sul e trazidas por suas famílias para Mato Grosso ainda crianças.

Tal pesquisa foi realizada a partir dos procedimentos da História Oral Temática, por meio de entrevistas com perguntas relacionadas ao posicionamento dos três filhos de colonizadores do município de Terra Nova do Norte, em Mato Grosso.

\begin{abstract}
História Oral Temática, por sua vez, está mais vinculada ao testemunho e à abordagem sobre algum assunto específico. A vida enquanto experiência individual tem, para esta vertente, significado menor e relativo. A História Oral Temática é um recorte da experiência com um todo e quase sempre - ainda não obrigatoriamente-, concorre com a existência de pressupostos já documentados e parte para "uma outra versão". Em alternativa diversa colabora para o preenchimento dos espaços vazios nas versões estabelecidas (BOM MEIHY, 1994, p. 57).
\end{abstract}

Deste modo, a atenção recai sobre as respostas dadas às questões feitas aos entrevistados. Questões que buscam verificar como os mesmos se identificam, se possuem a sensação de pertencimento para com a parte da terra onde residem, qual o sentido do espaço para eles e qual a perspectiva em relação ao local.

Ademais, Stuart Hall (2006) ao invés de falar da identidade como uma coisa acabada prefere falar em identificação, vendo-a como um processo em andamento. Argumenta que as sociedades da modernidade tardia caracterizam-se pela "diferença" e essa se particulariza pela posição que o sujeito pode exercer em seu processo de autorreconhecimento, a identificação.

No que diz respeito à identidade no sentido literal, trata-se do reconhecimento que o indivíduo tem de si mesmo, bem como as características que o identificam: nascimento, sexo, filiação e outros. Cabe a ressalva de que o sujeito se modifica no movimento decorrente do espaço ao qual ocupa. Para Hall (2006, p. 7) "as velhas identidades, que por tanto tempo estabilizaram o mundo social, estão em declínio, fazendo surgir novas identidades e fragmentando o indivíduo moderno, até aqui visto como um sujeito unificado".

Destarte, a identificação do discurso identitário dos entrevistados concernente à posição de suas identidades culturais e sociais - que relacionam as características de um povo ou de um indivíduo reconhecido por sua interação com membros da sociedade - fortalece a ideia de Hall (1996) acerca das identidades culturais. Vistas como pontos de identificação, 
pontos instáveis de identificação ou sutura feitos dentro dos discursos da história e da cultura, não uma essência e sim um posicionamento.

\section{Em Busca De Territórios}

A Diáspora, um dos aspectos de migrações, ocorre quando há dispersão de um grupo populacional de um território. Momento em que um determinado povo vê sua terra ocupada por outro, onde o invasor expulsa a população e a obriga ir à busca de territórios mais seguros para fixar-se e reorganizar suas vidas. Fato acontecido com os posseiros expulsos das terras indígenas Kaingang, nos finais da década de 70, no Estado do Rio Grande do Sul. Em busca de novos territórios, a solução encontrada foi a de procurar ajuda do governo estadual.

\footnotetext{
No início de maio de 1978 (madrugada do dia 05 para 06), ouvimos pelo noticiário das rádios que os índios estavam expulsando os colonos de todas as reservas do Sul do país. Mais de 2.500 famílias estavam sendo jogadas à beira da estrada aguardando providencias do governo. A expulsão começou pela reserva de Nonoai. O assunto começou a tomar o noticiário (SCHWANTES, 2008, p. 132).
}

Os governos compostos pela esfera estadual e federal juntamente com a Cooperativa Agropecuária Mista de Canarana Ltda. (COOPERCANA), liderada pelo pastor luterano Norberto Schwantes, apresentaram um projeto de assentamento dos colonos, levando os migrantes para a região do futuro município de Terra Nova do Norte, em Mato Grosso. Aqui, na busca de um novo espaço o sujeito se inseriu num processo de mudança que passou do físico ao psicológico, transformação que o obrigou a se reconstruir. Nesta concepção, a identidade acaba por ser uma construção líquida, fluida, porosa, considerada como um processo contínuo de redefinir-se, inventar e reinventar-se (BAUMAN, 2005, p. 13).

Entre os anos de 1978 e 1979, por intermédio do Projeto Terranova, foram transferidas aproximadamente 434 famílias para o novo assentamento na região amazônica. Houve a destinação e distribuição de 435 mil hectares de terras. 


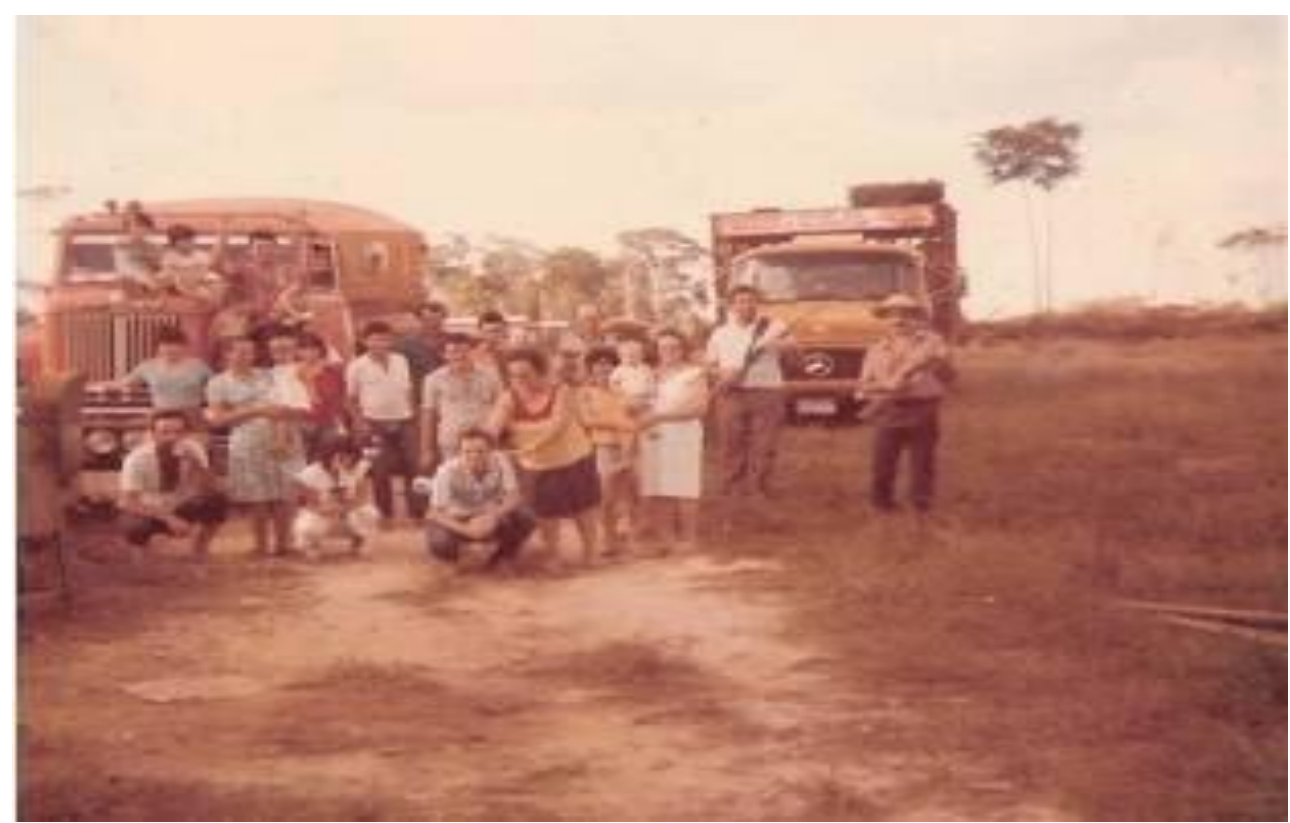

Fotografia 1 - Primeiras famílias que chegaram a Terra Nova do Norte-MT. Fonte: Neiva Frigeri, 1978.

A Coopercana abriu 1.062 lotes em nove agrovilas e, mesmo diante das dificuldades encontradas pelas primeiras famílias que chegaram ao lugar - mudança de clima, doenças e o difícil acesso devido à construção da BR163 em fase de abertura -, não foi o suficiente para 'matar o desejo' da conquista de novos territórios e espaços para a sobrevivência de muitos que chegaram a Terra Nova em 1978 e que permanecem até hoje.

Fazer da 'identidade' uma tarefa e objetivo do trabalho de toda uma vida, em comparação com a atribuição a estados da era pré-moderna, foi um ato de libertação - libertação da inércia dos costumes tradicionais, das autoridades imutáveis, das rotinas pré-estabelecidas e das verdades inquestionáveis (BAUMAN, 2005, p. 56).

Adiante, Terra Nova do Norte fica a 700 quilômetros da Capital do Estado de Mato Grosso no extremo norte, fazendo parte da região amazônica. 


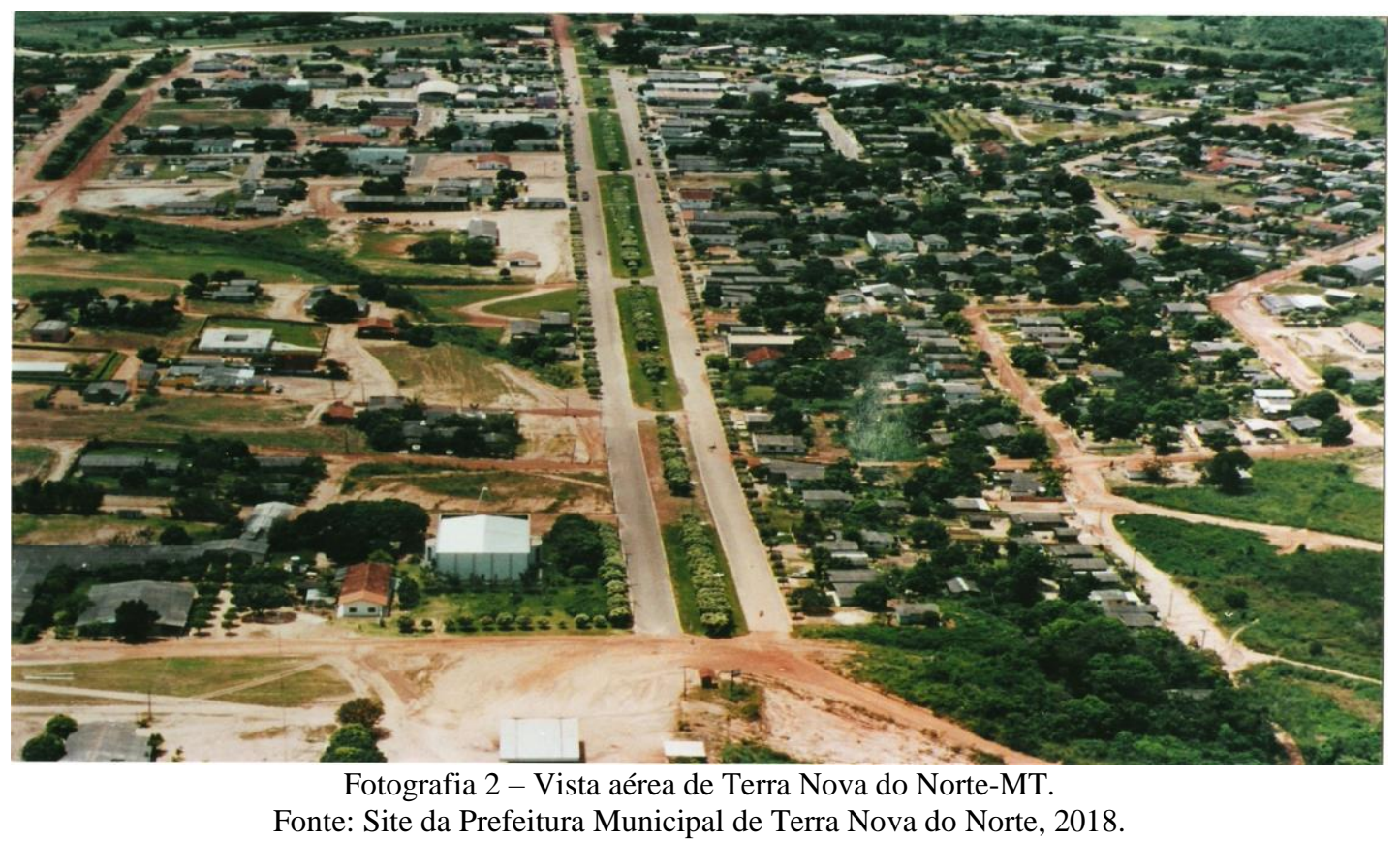

Localizada em região de floresta, Terra Nova possui terras férteis e uma economia baseada na agricultura, pecuária de leite, de corte e indústria madeireira. $\mathrm{O}$ município foi desmembrado de Colíder-MT em 13 de maio de 1986, por meio da Lei Estadual no 4.995.

[...] Terra Nova do Norte é o terceiro município a ter origem nos planos de Norberto para abrigar posseiros expulsos das reservas indígenas nos municípios gaúchos de Tenente Portela, Nonoai, Planalto, Miraguaí e Guarita em uma gleba de 435 mil hectares, até então pertencente ao Exército (SCHWANTES, 2008, p. 217).

No município, mesmo localizado na região centro-oeste do Brasil e extremo norte de Mato Grosso, percebe-se fortemente a presença da cultura gaúcha: o chimarrão, danças, vestimentas tradicionais, festas e costumes do povo. Também há muitas agrovilas, denominadas pelos colonos com os mesmos nomes dos locais onde moravam no Rio grande do Sul: Esteio, Planalto, Nonoai, Nova Guarita, Xanxerê, Miraguaí, Charrua, Minuano e Norberto Schwantes.

Essas identidades binárias, bipartidas, funcionam em uma espécie do reflexo narcísico do Um no Outro, confrontados na linguagem do desejo pelo processo psicanalítico de identificação. Para a identificação, a identidade nunca é um a priori, nem um produto acabado; ela é apenas e sempre o processo problemático de acesso a uma imagem da totalidade (BHABHA, 1998, p. 85). 


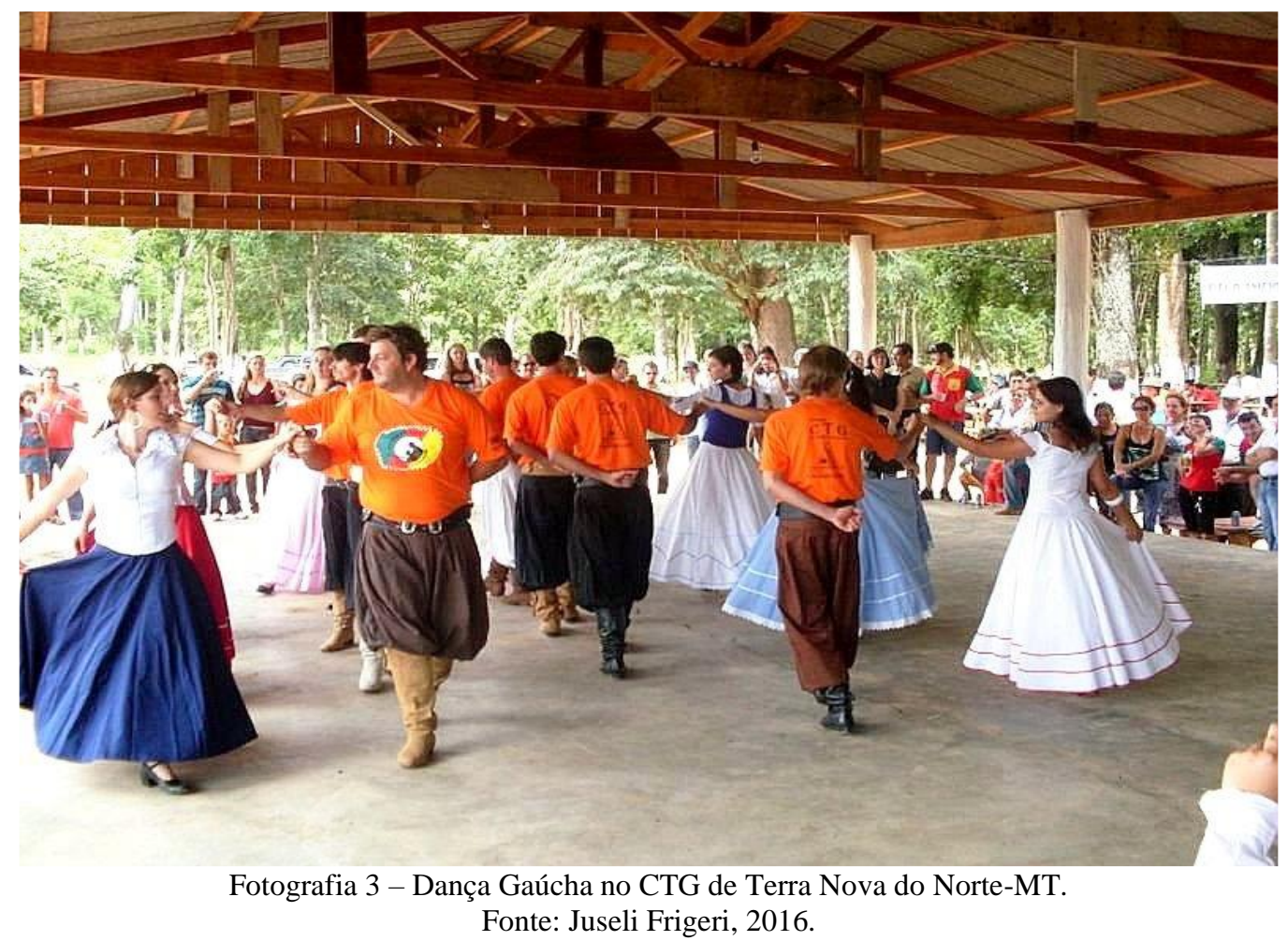

Assim, pensando nessa migração e partindo das considerações expostas constituiu-se a análise do discurso assumido sobre as identidades de três filhos de colonos, que nasceram no Rio Grande do Sul e cresceram em Mato Grosso. Isto, na intenção de verificar e refletir acerca da identidade assumida pelos mesmos e argumentos que as justificam.

\section{Discursos Identitários}

Juseli Frigeri, 46 anos, casada, formada em Administração, comerciante, nascida na cidade de Nonoai-RS em 17 de julho de 1972, filha dos colonos Luís Frigeri e Neiva Frigeri, vindos para Terra Nova com as primeiras famílias em 1978.

A vinda de nossa família se deu por motivo de meu pai querer um futuro melhor aos seus familiares, por isso veio em busca de novas terras. Me identifico gaúcha por tradição e mato-grossense por opção. Faço parte desta terra por ter fixado residência aqui, estudei e conquistei uma profissão, me casei e constitui família. Hoje talvez, não sinto vontade para ir embora pela oportunidade de vida que a cidade me deu e pela tranquilidade que tenho aqui para criar meu filho. Penso que Terra Nova é um município agrícola sem perspectiva de crescimento, mas a tranquilidade de vida que eu procuro encontro aqui (FRIGERI, 2018).

A entrevistada apresenta em seu discurso uma identificação gaúcha, sendo que viveu apenas seis anos no Rio Grande do Sul. Fato que vai de encontro à afirmação de que "dentro 
de nós há identidades contraditórias, empurrando em diferentes direções, de tal modo que nossas identificações estão sendo continuamente deslocadas" (HALL, 2006, p. 13).

Ainda, considera-se gaúcha pela admiração e permanência forte da cultura do Rio Grande do Sul em seu meio. Mesmo se incluindo como parte integrante de Terra Nova, pelas conquistas advindas do local, não se identifica terranovense. Entretanto, também não manifesta vontade de sair da cidade, por se tratar de um lugar bom para criar o filho e apesar de ser sem perspectiva de crescimento o mesmo oferta a tranquilidade que ela deseja. Neste ponto, a "identidade fixa e estável, foi descentrada, resultando nas identidades abertas, contraditórias, inacabadas, fragmentadas, do sujeito pós-moderno" (HALL, 2006, p. 46).

A segunda entrevistada, Marivânia Zamoner, 49 anos, casada, esteticista, natural de Ronda Alta-RS, filha dos colonos Luís Zamoner e Pierina Zamoner que vieram para Terra Nova em 1979.

\begin{abstract}
Viemos na busca de terra, já que esse era o desejo de todos que aqui chegaram na época. Vivendo aqui por muitos anos não deixo as tradições gaúchas como: churrasco, chimarrão [...]. Mato Grosso é o Estado que adotei para mim e o considero do coração. Me sinto parte de Terra Nova, me identifico mulher terranovense, pois acompanhei cada passo do desenvolvimento do município, é como se eu tivesse nascida aqui. Terra Nova, hoje, é meu porto seguro pela sua simplicidade, tranquilidade, cidade hospitaleira e gosto porque posso criar meus filhos longe de violências dos grandes centros (ZAMONER, 2018).
\end{abstract}

Percebe-se na fala de Dona Marivânia o orgulho de se identificar como sujeito matogrossense, pelas vivências e experiências adquiridas ao longo do tempo neste local. Veio em busca de terras como os demais, mas não consegue abandonar algumas tradições: a de sentarse de manhã ou tarde para conversar com a família e/ou amigos enquanto toma o chimarrão. Não quer esquecer ou deixar de manter a tradição do bom churrasco de domingo, costume de seus pais.

Nota-se que a mesma inclui-se explicitamente como parte desta terra, desta boa cidade que ajudou a construir, ainda se define como terranovense de coração. Por intermédio de suas palavras, reafirma-se o que Hugo Achugar (2006) estabelece em relação ao modo como o sujeito social pensa e/ou reproduz conhecimento, a partir de sua "história local", ou seja, a partir do modo que "lê" ou "vive" a "história local".

O último entrevistado, Volmir Zambenedete dos Santos, 46 anos, casado com Daniela Paola Buffon dos Santos, pai de 02 filhos (Gabriel Buffon dos Santos e Isadora Buffon dos Santos), agricultor, nascido na cidade de Nonoai-RS, filho dos colonos Domingos Alves dos 
Santos e Terezinha Zambenedete dos santos, vindos para Terra Nova com as primeiras famílias em 1978.

Meu pai foi desbravador aqui de Terra Nova e região, ele veio em 1978 e eu vim com minha mãe em 1979. Nasci em Nonoai-RS, vim para cá com nove anos, sou gaúcho de nascença, mas terranovense de coração por ter me criado aqui, me sinto um pouco gaúcho porque gosto da tradição, uso bombacha, danço no CTG (Centro de Tradições Gaúchas), mas meu coração é realmente mato-grossense. Amo esse lugar, tenho propriedades aqui, meu trabalho, minha vida [...]. Faço parte desta terra porque ajudei a construir Terra Nova, meu pai foi um dos primeiros que ajudou construir casas aqui juntamente a seu Luís Frigeri, Domingos Signor e o Gringo, eu era bem jovem, mas ajudava sempre nessas construções. Aqui é um lugar bom de se trabalhar, criar nossos filhos; é uma cidade tranquila, hospitaleira, as pessoas que vem para cá sentem-se bem e gostam do lugar devido a miscigenação que reside no município: gaúchos, mato-grossenses, nordestinos [...]. Temos algumas dificuldades relacionadas à produção, a agricultura e a pecuária, mas tenho boas expectativas em relação ao desenvolvimento da cidade devido às mudanças políticas e administrativas que estão acontecendo. Tenho certeza que aqui nós teremos um futuro brilhante (SANTOS, 2018).

Nesse discurso, Volmir demonstra o orgulho de ter sido filho de um colonizador e desbravador. Veio com seus pais em busca de território e conseguiu, tem posses aqui. Ama o lugar e se sente parte da terra, pois ajudou a construí-lo com seu pai e amigos. Atuou na construção de casas para os colonos no assentamento e continua a contribuir em prol da melhora da cidade. Nascido no Rio Grande do Sul, com nove anos passou a residir em Terra Nova. Se sente gaúcho de nascença, mas terranovense de coração.

Em nosso mundo de 'individualização' em excesso, as identidades são bênçãos ambíguas. Oscilam entre o sonho e o pesadelo, e não há como dizer quando um se transforma no outro. Na maior parte do tempo, essas duas modalidades líquidomodernas de identidade coabitam, mesmo que localizadas em diferentes níveis de consciência (BAUMAN, 2005, p. 38).

Ademais, o entrevistado afirma que o local é um lugar bom para trabalhar e criar os filhos, pois se trata de uma cidade tranquila, hospitaleira, aonde as pessoas que chegam são bem recebidas, sentem-se bem e gostam do lugar devido à miscigenação que reside no município: gaúchos, mato-grossenses, nordestinos.

A identidade plenamente unificada, completa, segura e coerente é uma fantasia. Ao invés disso, à medida que os sistemas de significação e representação cultural se multiplicam, somos confrontados por uma multiplicidade desconcertante e cambiante de identidades possível, com cada uma das quais poderíamos nos identificar ao menos temporariamente (HALL, 2006, p. 13). 
Ainda, seu Volmir ressalta que quem mora em Terra Nova enfrenta algumas dificuldades relacionadas à produção, a agricultura e a pecuária, mas tem esperanças, boas expectativas e a certeza de que os terranovenses terão um futuro brilhante.

\section{Conclusões}

A partir das contribuições teóricas e análises dos discursos identitários entende-se que a identidade não é algo fixo. A mesma encontra-se sempre em reconstrução, pois é movida pelas incertezas e construída pela heterogeneidade cultural e social. Como Hall (2006) estabeleceu, torna-se de uma "celebração móvel” à medida que se modifica continuamente diante de nossa representatividade nos sistemas culturais que nos cercam, definindo-se de maneira histórica ao invés de biologicamente.

No discurso da primeira entrevistada, percebe-se uma identidade intercambiante e não fixa, já que a mesma reside em Terra Nova do norte há 40 anos, gosta do local, se sente parte do mesmo; onde estudou, casou, constituiu família, conquistou seu espaço no mercado de trabalho e não quer sair do lugar devido às oportunidades e a tranquilidade que tem. No entanto, se identifica gaúcha.

O segundo discurso apresenta uma afirmação e uma identificação maior com o espaço que ocupa, considerando Mato Grosso como o estado do coração. Também se sente parte de Terra Nova, se identificando como mulher terranovense, pois acompanhou o desenvolvimento do município e tem a cidade como porto seguro, pela tranquilidade e hospitalidade proporcionada. Ainda, verifica-se uma identidade em movimento e não estática, quando afirma que, mesmo vivendo por muitos anos em Mato Grosso, não consegue deixar as tradições gaúchas.

Quanto ao discurso de Volmir Zambenedete, vê-se o orgulho ao se identificar terranovense e filho de um desbravador de Terra Nova e região. O mesmo se sente parte da terra, pois ajudou a construí-la. Mas também deixa transparecer em sua fala que se identifica como um pouco gaúcho porque gosta e admira as tradições gaúchas. O que vai de encontro à afirmativa de Bauman (2005) de que o 'pertencimento' e a 'identidade' são mutáveis, sendo as atitudes e escolhas tomadas pelo indivíduo, ao decorrer de sua vida, variáveis cruciais para ambos os fatores.

Ademais, o objetivo aqui proposto foi o de trazer uma discussão acerca dos discursos identitários dos entrevistados concernentes às suas identidades, uma vez que residem há muito tempo nesse Município de Mato Grosso, sendo que são nascidos em outro Estado. Onde se 
constatou que, conforme Hall (2006) salienta, a identidade trata-se inegavelmente de uma questão histórica e a sociedade é composta de inúmeros e distintos povos pertencentes originalmente a outro lugar.

Fato presente nos discursos dos entrevistados aqui apresentados, pois todo processo histórico ao qual passaram resultou em aspectos determinantes para a formação de suas identidades, bem como na identificação assumida pelos mesmos. Neste sentido, Bauman (2005) colabora quando defende que a identidade é o resultado não apenas interno do indivíduo, mas também resultado de suas interações e relações sociais.

Desta maneira, conclui-se que os discursos de identidades culturais são passíveis de mudanças constates. Não sendo uma essência, mas um posicionamento de cada indivíduo, que longe de suas origens culturais passa a conviver com outras identidades, buscando novas formas de interagir com a sociedade e com o mundo. Tais conflitos internos e externos realimentam as necessidades do sujeito em compreender sua identificação como um ser social e agente de sua própria construção.

\section{Referências}

ACHUGAR, Hugo. Planetas sem boca: escritos efêmeros sobre arte, cultura e literatura. Tradução: Lyslei Nascimento. Belo Horizonte: UFMG, 2016.

BAUMAN, Z. Identidade. Entrevista a Benedetto Vecchi. Rio de Janeiro: J. Zahar, 2005.

BHABHA, Homi K. O local da cultura. Belo Horizonte: Editora da UFMG, 1998.

FRIGERI, Neiva. Primeiras famílias que chegaram a Terra Nova do Norte-MT. Fotografia 1, 1979.

FRIGERI, Juseli. Juseli Frigeri: depoimento [jun. 2018]. Entrevistador: Vanderley da Silva. Terra Nova do Norte, MT, 2018. 01 gravador de celular. Entrevista concedida para a escrita do artigo Discursos identitários e a posição como sujeito terranovense.

Dança Gaúcha no CTG de Terra Nova do Norte-MT. Fotografia 3, 2016.

HALL, Stuart. A identidade cultural na pós-modernidade. Tradução: Tomaz Tadeu da Silva, Guaracira Lopes Louro. 11. ed. Rio de Janeiro-RJ: DP \& A, 2006.

Identidade cultural e diáspora. In: Revista do Patrimônio Histórico e Artístico

Nacional. Rio de Janeiro, IPHAN, 1996, p. 68-75.

MEIHY, J. C. S. B. Definindo história oral e memória. São Paulo: Cadernos CERU, 1994. 
SANTOS, Volmir Zambenedete dos. Volmir Zambenedete dos Santos: depoimento [jun. 2018]. Entrevistador: Vanderley da Silva. Terra Nova do Norte, MT, 2018. 01 gravador de celular. Entrevista concedida para a escrita do artigo Discursos identitários e a posição como sujeito terranovense.

SCHWANTES, Norberto. Uma cruz em Terra Nova. Brasília: Edição do Autor, 2008.

SITE PREFEITURA MUNICIPAL DE TERRA NOVA DO NORTE. 2018. Vista aérea de Terra Nova do Norte-MT. Fotografia 2. Disponível em <http://www.terranovadonorte.mt.gov.br>. Acesso em: 15 abr. 2018.

ZAMONER, Marivânia. Marivânia Zamoner: depoimento [jun. 2018]. Entrevistador: Vanderley da Silva. Terra Nova do Norte, MT, 2018. 01 gravador de celular. Entrevista concedida para a escrita do artigo Discursos identitários e a posição como sujeito terranovense. 